\section{SUMMARY AND CONCLUSION}

Five days after Sydney's successful Olympic and Paralympic bid application was announced in Monte Carlo, the first meeting of the Australian Medical Disaster Coordination Group (AMDCG), ${ }^{9}$ a sub-group of the Australian Health Ministers Advisory Council (AHMAC) was held at Alice Springs. The seventh AMDCG meeting was held recently in Melbourne (2-4 April 2000). The successful collaborative outcomes of this seven-year period reported to AHMAC include authoritative and up to date publications in the fields of disaster medicine, ${ }^{10}$ mass gatherings, ${ }^{11}$ and chemical, biological and radiological hazards. ${ }^{12}$

NSW Health has devoted substantial resources to the accepted emergency management principles of planning, preparation and prevention outlined in these and other documents, in progressively developing its strategic plan for service delivery during the Games.

Counter disaster planning, expressed through NSW HEALTHPLAN and supporting Olympic Games Standing Operating Procedures, has been framed to ensure that an appropriate and effective response can be mounted in the event of any untoward happening.

\section{REFERENCES}

1 NSW Government Olympic Bid Document. Sydney: NSW State Government, 1992; Para 7.2.4.

2 NSW Department of Health. New South Wales Multiple Casualty, Emergency and Disaster Medical Response Plan (MEDPLAN). Sydney: NSW Department of Health, July, 1990.
3 NSW Department of Health. NSW Health Services HEALTHPLAN-Functional Area Supporting Plan to the New South Wales State Disaster Plan (NSW DISPLAN). Sydney: NSW Department of Health, December 1996. State Health Publication Number PH960098.

4 Daley, P. Terror alert on Anthrax. Sunday Age, Melbourne, 4 June 2000.

5 Clancy T. Rainbow 6. Melbourne: Penguin Books, 1998.

6 International Union of Microbiological Societies. Proceedings of the Bioterrorism Symposium, 14 August 1999, Darling Harbour Convention Centre NSW. Audio cassettes. Padstow, Sydney: Quickopy Audio Recording Services, 1999.

7 Evangeli A. Disaster Planning-Bioterrorism and the Olympics. Medicine Today 1 July 2000: 148-153.

8 Flynn MJ. Editorial: Sydney and the Games: what are the risks? Microbiology Australia September 1999: (20)4.

9 Department of Health Housing, Local Government and Community Services. Report of the Australian Medical Disaster Coordination Group Meeting, Alice Springs 2830 September 1993. Canberra: Commonwealth of Australia, 1993.

10 Emergency Management Australia, Department of Defence. Australian Emergency Manuals Series Part III, Volume 1 Manual 2, Disaster Medicine. Canberra: Commonwealth of Australia, 1999.

11 Emergency Management Australia, Department of Defence. Australian Emergency Manuals Series Part III, Volume 2 Manual 2, Safe and Healthy Mass Gatherings. Canberra: Commonwealth of Australia, 1999.

12 Emergency Management Australia, Department of Defence. Australian Emergency Manuals Series Part III, Volume 2 Manual 3, Health Aspects of Chemical, Biological and Radiological Hazards (Provisional Edition). Canberra: Commonwealth of Australia, 2000.

\title{
HEALTH SURVEILLANCE DURING THE SYDNEY 2000 OLYMPIC AND PARALYMPIC GAMES
}

Sarah Thackway,

on behalf of the Olympic Surveillance Working Party

Olympic Planning Unit

NSW Department of Health

This article describes the Olympic Surveillance System developed by NSW Health to monitor the health of the population of Sydney during the Sydney 2000 Olympic and Paralympic Games. The surveillance system will be the most comprehensive ever undertaken in NSW and will provide more coverage than the systems used during previous Olympic Games.

\section{HEALTH SURVEILLANCE DURING MASS GATHERINGS}

Mass gatherings, such as sporting events and outdoor celebrations, require the provision of medical services for the large numbers of people who attend. ${ }^{1-3}$ In addition, the crowding of people into relatively closed environments may promote the transmission of infectious agents spread via the respiratory route (for example, measles and influenza). ${ }^{4-5}$

The provision of medical and public health services is enhanced by epidemiological surveillance, an important tool implemented to monitor unusual patterns of illness. Surveillance systems act as an early warning to detect communicable disease outbreaks that can occur during these gatherings, as well as unusual patterns of noninfectious conditions such as injuries that may require public health intervention. In previous Olympic Games, a variety of surveillance systems have been implemented to monitor for outbreaks of disease. ${ }^{6-8}$ 


\section{HEALTH SURVEILLANCE DURING THE SYDNEY 2000 OLYMPIC AND PARALYMPIC GAMES}

Apart from the health risks associated with mass gatherings, the Games will be held during Spring, a time generally associated with an increased incidence of certain communicable diseases. Of specific concern are foodborne and water-borne diseases and conditions spread through droplets, such as pertussis and measles. Consequently, existing surveillance systems have been enhanced to create the Olympic Health Surveillance System (Figure 3). This system enables NSW Health to rapidly detect increases in reports of communicable diseases and any unusual patterns of illness or injury. Appropriate action will then be initiated to prevent further morbidity.

The overall strategy is to build up a total picture of health across Sydney during the Games period using a number of formal data collection systems and informal reporting mechanisms.

\section{COMPONENTS OF THE OLYMPIC HEALTH SURVEILLANCE SYSTEM}

Notifiable Diseases Database (NDD)

Under the NSW Public Health Act 1991, medical practitioners, hospital chief executives (or general managers), pathology laboratories, directors of child care centres and school principals are required to notify certain medical conditions to the nearest public health unit. These data are used to track the incidence of communicable diseases across the State and form the basis of surveillance reports published in the NSW Public Health Bulletin.

The Notifiable Diseases Database (NDD) will continue to be used to detect outbreaks of communicable diseases. During the Games period, however, enhanced surveillance will be undertaken, including active laboratory surveillance of acute diseases and enhanced reporting structures. These enhancements are described in more detail in the article by Menzies on page 146 .

\section{Emergency Department Olympic Surveillance System}

Fifteen Emergency Departments have been selected as sentinel sites for the NSW Emergency Department Olympic Surveillance System (EDOSS): Auburn, Concord Repatriation, Liverpool, Nepean, Prince of Wales, Royal Prince Alfred, St Vincent's, Sydney, Royal North Shore, Ryde, Sydney Children's, St George, The New Children's and Westmead.

A database has been designed to capture information from selected hospitals on patients presenting with the following conditions or symptoms:

- diarrhoea (with or without blood-where suspected cause is an infectious or chemical agent)
- vomiting (where suspected cause is an infectious or chemical agent)

- pneumonia

- influenza-like illness

- pertussis

- meningitis

- acute viral hepatitis

- febrile illness with a rash

- injuries occurring outside of the home environment

- illicit drug-related episodes.

Data surveillance officers in the emergency departments will collect the information in 'real-time' and forward it electronically to the NSW Department of Health each day.

Mass gatherings in Sydney over the past year, such as the Olympic Test Events (September 1999), New Year's Eve (1999-2000) and the Sydney Gay and Lesbian Mardi Gras (March 2000) provided opportunities to trial the systems' operational capability and detect issues related to target case identification and data collection. In May 2000, a full dress rehearsal of the system was successfully undertaken. Other methods used to ensure data quality and increase validity were: the conduct of a validation study, provision of in-services to emergency department clinical staff, the development of a detailed procedures manual in plain English and training of data surveillance officers.

\section{Health surveillance on cruise ships}

Health data will also be collected from the nine cruise ships berthed in Sydney during the Games. This system is described in detail in the article by Waples et al. on page 150 .

\section{SOCOG Medical Encounters Reporting System}

During the Olympic Games, SOCOG will operate a medical encounters reporting system (MERS). This system will record basic medical data for all presentations to medical centres and St John's Ambulance Officers located at Olympic venues.

\section{Environmental monitoring}

Reports from environmental health inspection teams inside Olympic Venues (see the article by Banwell on page 147) will be relayed to the NSW Department of Health each day.

\section{Food safety monitoring}

Reports from food safety inspection teams inside Olympic venues (see the article by Holroyd et al. on page 151) will be relayed to the NSW Department of Health each day.

\section{Global epidemic surveillance}

In the lead up to and during the Games period, it will be essential to be aware of current infectious disease outbreaks occurring around the world. Data from various Web and email sites will be used for exchanging outbreak information. 
FIGURE 3

NSW HEALTH OLYMPIC SURVEILLANCE SYSTEM

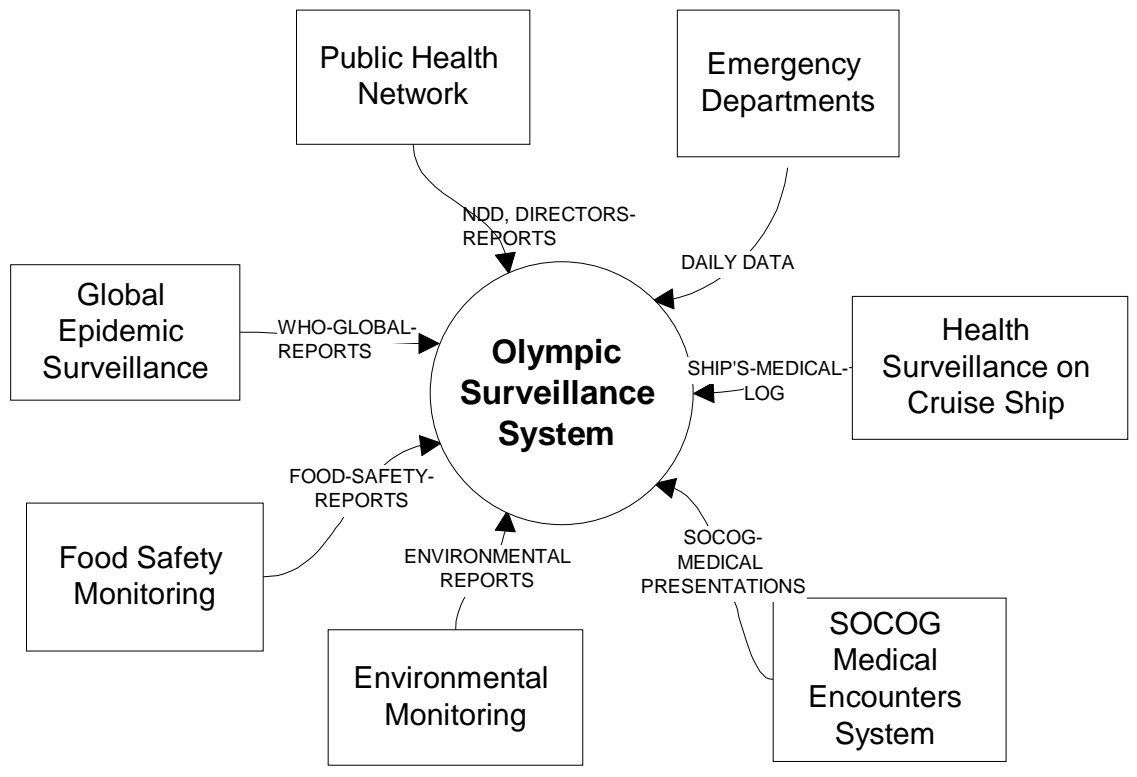

Data from the Olympic Health Surveillance System will be processed in the NSW Department of Health. The Epidemiology and Surveillance Branch's data warehouse (the Health Outcomes Information Statistical Toolkit, or HOIST) will automatically generate daily reports for the major components of the system. A team of experts from the NSW Department of Health and the six metropolitan Sydney public health units will analyse surveillance reports daily over the Games period, and will activate appropriate public health responses.

The Olympic Health Surveillance System developed for the Sydney 2000 Olympic and Paralympic Games is the most complete ever developed for such an event. It will serve as a model for health surveillance during future mass gatherings in Sydney, and will inform the planning for health surveillance in future Olympic games.

The outcomes of the Olympic Health Surveillance System will be reported in forthcoming editions of the Bulletin.

\section{ACKNOWLEDGEMENTS}

The members of the Olympic Surveillance Working Party are: Louisa Jorm (Chair), Pam Albany, Mark Bartlett, Sue Campbell-Lloyd, Kerry Chant, Tim Churches, Valerie Delpech, Bernie Gromek, John Kaldor, Jeremy McAnulty, Rob Menzies, Ross O’Donoghue, Jim Snyder, Lee Taylor, Sarah Thackway, Maria Visotina, Peter Waples, Rachel Zordan.
The Working Party acknowledges the significant contribution by Tony Butler in the initial development of this system. Devon Indig and Lara McIntyre also made valuable contributions.

\section{REFERENCES}

1. Green GB, Burnham G. Health care at mass gatherings. JAMA 1998; 279: 1485-6.

2. Leonard RB. Medical support for mass gatherings. Emerg Med Clin North Am 1996; 14: 383-397.

3. Thompson JM, Savoia G, Powell G et al. Level of medical care required for mass gatherings: the XV Winter Olympic Games in Calgary, Canada. Ann Emerg Med 1991; 20: 38590.

4. Goodman RA, Thacker SB, Solomon SL. Infectious diseases in competitive sports. JAMA 1994; 271: 862-867.

5. Ehresmann KR, Hedberg CW, Grimm MB, et al. An outbreak of measles at an international sporting event with airborne transmission in a domed stadium. J Infect Dis 1995; 171: 679-83.

6. Meehan P, Toomey KE, Drinnon J, et al. Public Health Response for the 1996 Olympic Games. JAMA 1998; 279: 1469-1473.

7. Wetterhall SF, Coulombier DM, Herndon JM, et al. Medical Delivery at 1996 Olympic Games. JAMA 1998; 279: 14631468.

8. Weiss BP Mascola L, Fannin SL. Public health at the 1984 Summer Olympics: the Los Angeles County experience. Am J Public Health 1988; 78: 686-688. 